\title{
Antiulcer Property of Mussaenda philippica
}

\author{
Rasmita Jena*, Durga Madhab Kar, Diptirani Rath, Kaushik Sur Roy, Goutam Ghosh
}

\section{Rasmita Jena*, Durga Madhab Kar, Diptirani Rath, Kaushik Sur Roy, Goutam Ghosh}

Department of Pharmacology, School of Pharmaceutical Sciences, $S$ ' $O$ ' (A Deemed to be University), Bhubaneswar, Odisha- 751003, INDIA.

\section{Correspondence}

Miss. Rasmita Jena

Ph. D Research Scholar, Department of Pharmacology, School of Pharmaceutical Sciences, S 'O' (A Deemed to be University), Bhubaneswar, Odisha- 751003, INDIA.

Phone no : +919777643666

E-mail: rasmita05little@gmail.com

\section{History}

- Submission Date: 09-11-2018;

- Review completed: 03-01-2019;

- Accepted Date: 14-01-2019

DOI : 10.5530/pj.2019.11.96

Article Available online

http://www.phcogj.com/v11/i3

\section{Copyright}

(c) 2019 Pharmacognosy Journal. This is an open-access article distributed under the terms of the Creative Commons Attribution 4.0 International license.

\begin{abstract}
Introduction: Mussaenda philippica (Rubiaceae) is a shrub distributed in all the planes of India, Philippines and South-East Asia. Its synonyms are M. grandiflora, M. acutifolia, M. frondosa etc. The plant is preferred as medication for the treatment of jaundice, dysentery, stomachache and influenza. The current study was based on the evaluation of antiulcer property of M. philippica leaves extract. Methods: The methods used were pylorus ligated, ethanol induced and $0.2(\mathrm{M}) \mathrm{NaOH}$ induced ulcer in rats. Results: In pylorus ligation model, aqueous extract $(200 \mathrm{mg} / \mathrm{kg})$ produced a substantial reduction in ulcer index followed by decrease in gastric volume, total acidity associated with a raise in $\mathrm{pH}$, which, confirmed that tested extract of the plant act by altering the mucosal barrier Thus, the gastro protective effect of this extract may be due to the presence of flavonoid in the plant. In the same way, aqueous extract of the plant showed significant effect against ethanol induced gastric ulcer in rat as compared to methanol-treated group, which, may be due to leukotriene antagonistic effect or the inhibition of 5-lipooxygenase pathway. In $\mathrm{NaOH}$ induced ulcer model, aqueous extract of M. philippica revealed significant antiulcer effects on the basis of $\mathrm{pH}$ effect and ulcer index in rats. The anti-ulcerogenic and anti-secretory effect of the tested $M$. philippica leaves extracts point out its possible cyto-protective effect. Conclusion: In conclusion the aqueous extract of M. philippica leaves possess potential antiulcer activity in experimental rat models.
\end{abstract}

Key words: Anti-secretory, Gastric volume, Methanol extracts, Mussaenda philippica, Pylorus ligation.

\section{INTRODUCTION}

The world wide use of medicinal plants has gained additional impact due to its natural origin and high therapeutic implications. Mussaenda philippica 'Aurorae' belonging to family Rubiaceae is a shrub, having small tube like flowers, oblong-lanceolate, dark green, glossy leaves. It is well distributed throughout India, South East Asia and Philippines. ${ }^{1}$ This plant is used for dysentery, jaundice, emollient, snake bites, stomach-ache and influenza as folk remedies. ${ }^{1-2}$ Mussaenda genuses have various species having distinct novel phytoconstituents which are preferred for the treatment as anti-oxidant, antimicrobial, anti-inflammatory agents. A rich resource for natural products is provided by ethno-botany which shows a new-step stone for research in drug and its development. ${ }^{3}$ Three different iridoid glycosides like 5- hydroxy davisiosides, 4-acetoxy-7-methoxy secologanin and 6-methoxy mussaenoside and two flavones, 5, 7, 4-tri-hydroxy-3-methoxy flavone and 5, 7-di-hydroxy-6, 3, 4-tri-methoxy flavones were identified from of M. philippica sepal as phyto-constituent. ${ }^{4}$ In medicine, peptic ulcer is characterised as lesions in mucosa which penetrate the mucosa layer by forming a crack surrounded by acute and chronic inflammation. ${ }^{5}$ Behind the disruption of equilibrium between aggressive factors and defensive factors the major factors are hyper secretion of acid- pepsin, Helicobacter pylori, sometimes idiopathic due to usage of tobacco, non-steroidal anti-inflammatory drugs, rapid gastric emptying, psychological stress and Zollinger - Ellison syndrome where there is an elevated and uncontrollable production of acid might lead to formation of ulcer. ${ }^{6}$ For the treatment of gastrointestinal disorders, including gastric ulcers numerous medicinal herb and plants have been preferred in traditional medication system. As this plant contains flavonoids, ${ }^{7}$ which promoted the researchers to investigate the anti-ulcer effect in $M$. philippica. The plant parts are being used in folkloric medication by the people for the treatment of different types of GIT disorders. The prevailing investigation was focused on the evaluation of antiulcer property of $M$. philippica by following different experimental animal models.

\section{MATERIALS AND METHODS}

\section{Chemicals}

Wagner's reagent, Frothing reagent, $\mathrm{FeCl}_{3}$ reagent, Schinoda's reagent, Keller Killiani reagent, Salkowski reagent, Molish's reagent, Salkowski reagents, methanol, ranitidine, Sodium Hydroxide, ethanol, chloroform were of analytical grade and purchased. 


\section{Plant Materials}

Fresh leaves were collected in the early morning from the campus of Siksha 'O' Anusandhan, Bhubaneswar, Odisha in between July and August. This plant was identified and authenticated by the Principal Scientist P.C. Mohanty in Regional Plant Resource Center, Bhubaneswar.

\section{Experimental Animals}

All the animals were procured from the registered breeder M/s Saha Enterprise, Kolkatta and stored in the animal house of the institute. Wister albino rats of both sexes weighing around 120 - 150 gm were used and kept in polycarbonate cages, in twelve hour light followed by twelve hour dark condition. Standard pellet diets were used and water ad libitum at room temperature i.e. $25^{\circ} \mathrm{C}-30^{\circ} \mathrm{C}$, with $45 \%-55 \%$ humidity. The healthy animals of either sex were acclimatized for $72 \mathrm{~h}$ before commencement of the experiment. All the animal experiments were approved by the Institutional animal Ethics Committee (IAEC), bearing approval number 17(S) /SPS/IAEC/SOAU and registration number 1171/C/08/CPCSEA and executed as per CPCSEA guidelines. ${ }^{8}$

\section{Preparation of Extract}

The extraction was prepared from fresh leaves. The leaves were washed thoroughly to remove waste debris and then subjected for drying under the shed at room temperature for 20 days. The dried leaves was homogenized into course powder by mechanical grinder and passed through sieve number 40 . The course powder was De-fatted using petroleum ether in a round bottom flask to prevent the loss of thermo sensitive constituents, at room temperature for 2 days. The defatted materials were subsequently extracted using methanol and water.

\section{Methanol Extraction}

In a round bottom flask, the defatted course powder was taken and it was extracted by using methanol at room temperature for $72 \mathrm{~h}$. After completion of extraction process, further the extracts was filtered by using whatman's filter paper and collected. In a beaker the crude extract was decanted and the concentrated. The extract was kept separately in freeze for further study by using an air tight container.

\section{Aqueous Extraction}

In a round bottom flask, the defatted course powder was taken and it was extracted by using distilled water at room temperature for $48 \mathrm{~h}$ followed by slight heat for preservation to avoid bacterial contamination. After completion of extraction process, further, the extracts was filtered by using whatman's filter paper and collected. In a beaker the crude extract was decanted and the concentrated. The extract was kept separately in freeze for further study by using an air tight container.

\section{Phytochemical Screening}

Phytochemical screening of M. philippica leaf extract was performed qualitatively to determine the chemical constituents such as alkaloids (Wagner's reagent test), saponins (Frothing test), tannins $\left(\mathrm{FeCl}_{3}\right.$ test), flavonoids (Schinoda's test), phenols, glycosides (Keller Killiani test), steroids (Salkowski test), carbohydrates (Molish's test), terpinoids (Salkowski test) according to the standard protocol. ${ }^{9}$

\section{Study on Acute toxicity}

A study on acute toxicity was carried out on 12 hours fasted healthy Wister albino rat of eight groups of three rats each of both sex followed by the principles of Organization for Economic Co-operation and Development (OECD guidelines 423). Major objective of this type of toxicity study was to put paid to an idea of any toxicity of $M$. philippica leaf extract before carry out the entire study.

\section{Pharmacological Studies}

Experimental Design

A total of 72 animals (either sex) were used for the evaluation of antiulcer activity using three experimental models. Twenty four rats were used in each experimental and grouped in to four of six animal each. Group I (Control) received solvent at $10 \mathrm{ml} / \mathrm{kg}$ dose: Group II (standard) received Ranitidine at dose level of $200 \mathrm{mg} / \mathrm{kg}$ : Group III and IV, served as test group and treated with aqueous extract and methanolic extract at a dose level of $200 \mathrm{mg} / \mathrm{kg}$.

\section{Pylorus Ligated Gastric Ulcer}

This model was selected for the study of anti-secretory activity under light anaesthesia. For control group distilled water and for standard group ranitidine $(200 \mathrm{mg} / \mathrm{kg}$ ) were administered orally. Methanol and aqueous extracts were administered orally immediate after $4 \mathrm{~h}$ and later the pylorus ligated animals were sacrificed. Removal of stomach was carried out with care followed by the collection of gastric content. Centrifugation of gastric content was carried out at $10000 \mathrm{rpm}, 4^{\circ} \mathrm{C}$ for $15 \mathrm{~min}$. Free and total acidity content were determined from the supernatant by titration with $0.1 \mathrm{~N}$ Sodium Hydroxide and expressed as mEq/ $\mathrm{L} / 100 \mathrm{~g}$. Evaluation of gastric ulcer was performed by cutting the stomach and pinning on a soft board from the larger curvature to calculate the ulcer index. The ulcer index was measured by using scoring technique as 0 - Normal; 0.5 - Red coloration; 1.0 - Spot ulcers; 1.5 - Hemorrhagic Streaks and $2.0-$ Ulcer $>3$ but $<5 ; 3.0-$ Ulcer $>5$.

\section{Ethanol Induced Gastric Ulcer}

This model was selected for the study of cyto-protective activity. Rats were starved under standard condition prior to $48 \mathrm{~h}$ for the experiment. Before the use to confirm of empty stomach, they were set aside in raised floors of broad wire mesh cages for the prevention of corophagy. ${ }^{10}$ Distilled water was supplied to the rat before $1 \mathrm{~h}$ of experiment for the prevention excessive dehydration during fasting. In day 1 , both extracts were administered at a dose of $200 \mathrm{mg} / \mathrm{kg}$ orally to group - III and IV. In day 2, next dose was administered $2 \mathrm{~h}$ before of ethanol $50 \%(\mathrm{v} / \mathrm{v})$ administration in distilled water $(10 \mathrm{ml} / \mathrm{kg})$. Equal volume of distilled water was administered to control group with instead of extract but get ethanol in the same schedule and at same time intervals. The standard group was administered with ranitidine $(200 \mathrm{mg} / \mathrm{kg})$. One hour after the ethanol administration by using chloroform all animals were sacrificed followed by quick removal of stomach. The gastric lesion index was determined by measuring the length of each lesion in $\mathrm{mm}$. The percentage protection was calculated in \% of inhibition of Ulceration by using the following formula. ${ }^{11}$

$$
\% \text { of protection }=\frac{(\text { Ulcer index control }- \text { Ulcer index test })}{\text { Ulcer index control }} \times 100
$$

\subsection{Sodium Hydroxide Induced Ulcer}

Animals were fasted with distilled eater only for $48 \mathrm{~h}$. The necrotizing agent i.e. $2 \mathrm{M}$ sodium hydroxide $(1 \mathrm{ml}$ each) was administered orally after $30 \mathrm{~min}$ of test dose administration to each group. After $1 \mathrm{~h}$ animals were sacrificed and the summation of erosion length was determined as an index of lesion.

\section{Statistical Analysis}

The results are expressed as mean \pm variance and statistical significance by means of ANOVA followed by Dunnett's t-test.

\section{RESULTS}

\section{Extraction of Plant Materials}

The percentage yield of methanol extract is: $27.8 \% \mathrm{v} / \mathrm{v}$, the percentage yield of methanol extract is: $27.8 \% \mathrm{v} / \mathrm{v}$ 


\section{Phytochemical Study}

Preliminar phytochemical screening was performed and confirmed the presence of tannins, triterpinoids, saponins, flavonoids, phenols and glycosides while carbohydrates, steroids and alkaloids were not found.

\section{Study on Acute Toxicity}

At the highest dose ranges from $500-4000 \mathrm{mg} / \mathrm{kg}$ of body weight, where no signs of acute toxicity and mortality were found after observation of $72 \mathrm{~h}$ and even up to 14-days of observation. Then the dose was fixed at $1 / 20^{\text {th }}$ of the lethal dose $(200 \mathrm{mg} / \mathrm{kg})$.

\section{Effect of Extracts of M. philippica Leaves in Pylorus Ligated Ulcer Model}

The data (Table 1) stated that standard ranitidine and the aqueous extract indicates a significant $(p<0.001)$ decrease in ulcer index i.e. 1.93 and 2.35 as compared to control group having 5.73 ulcer index, while the methanol extract showed no significant reduction in ulcer index i.e. 3.63. Reduction in $\mathrm{pH}$ of gastric content was observed in aqueous extract and standard drug as compared to the standard group while methanol extract indicates significantly less effect but among the treated groups the F value indicates the significance $(p<0.001)$ difference. Effect of gastric volume and free acidity content of control group are $7.18 \mathrm{mEq} / \mathrm{L} / 100 \mathrm{~g}$ and total acidity content of $8.4 \mathrm{mEq} / \mathrm{L} / 100 \mathrm{~g}$ while methanol extract indicates no changes significantly when compared to solvent control group; among the treated groups the F value showed the significance $(p<0.001)$ difference.

\section{Effect of Extracts of M. philippica Leaves in Ethanol Induced Ulcer rat Model}

The data (Table 2) stated that standard ranitidine and the aqueous extract indicates decrease in ulcer index i.e. 2.13 and 3.01 significantly $(p<0.001)$ as compared to control group having 5.82 ulcer index, while the methanol extract indicates no significant reduction in ulcer index i.e. 4.16. Reduction in $\mathrm{pH}$ of gastric content was observed in aqueous extract and standard drug when compared to the standard solvent group and methanol extract showed significantly less effect but among the treated groups the F value showed the significance $(p<0.001)$ difference.

\section{Effect of Extracts of M. philippica Leaves in $\mathrm{NaOH}$ Induced Rat Ulcer Model}

The data (Table 3 ) stated that standard ranitidine and the aqueous extract indicates decrease in ulcer index i.e. 2.28 and 3.12 significantly $(p<0.001)$ as compared to control group having 6.4 ulcer index, while the methanol extract showed no significant reduction in ulcer index i.e. 4.23. Reduction in $\mathrm{pH}$ of gastric content was observed in aqueous extract and standard drug when compared to the standard solvent group and methanol extract showed significantly less effect.

Table 1: Effect of extracts of Mussaenda philippica leaves in pylorus ligated ulcer model.

\begin{tabular}{|c|c|c|c|c|c|c|c|}
\hline Group & Treatment and dose & $\begin{array}{c}\text { Gastric } \\
\text { volume/100 }\end{array}$ & $\mathrm{pH}$ & Ulcer index & $\begin{array}{l}\text { Free acidity } \\
\mathrm{mEq} / \mathrm{L} / 100 \mathrm{~g}\end{array}$ & $\begin{array}{l}\text { Total acidity } \\
\mathrm{mEq} / \mathrm{L} / 100 \mathrm{~g}\end{array}$ & $\%$ of protection \\
\hline I & Control $10 \mathrm{ml} / \mathrm{kg}$ & $4.51 \pm 0.45$ & $2.01 \pm 0.68$ & $5.73 \pm 0.61$ & $7.18 \pm 0.54$ & $8.40 \pm 0.72$ & - \\
\hline II & Ranitidine $200 \mathrm{mg} / \mathrm{kg}$ & $3.62 \pm 0.32^{*}$ & $4.16 \pm 0.82^{*}$ & $1.93 \pm 0.15$ & $4.80 \pm 0.15$ & $5.39 \pm 0.15^{* *}$ & 66.31 \\
\hline III & Aq. Extract $200 \mathrm{mg} / \mathrm{kg}$ & $4.05 \pm 0.49$ & $3.94 \pm 0.61^{*}$ & $2.35 \pm 0.16$ & $5.05 \pm 0.42^{\star *}$ & $6.24 \pm 0.52^{\star *}$ & 58.98 \\
\hline \multirow[t]{2}{*}{ IV } & Me. Extract $200 \mathrm{mg} / \mathrm{kg}$ & $4.31 \pm 0.31$ & $3.01 \pm 0.40^{* *}$ & $3.63 \pm 0.18^{*}$ & $6.32 \pm 0.48^{*}$ & $7.11 \pm 0.56^{* *}$ & 36.64 \\
\hline & $F(3,20)$ & 2.14 & $13.04^{*}$ & $41.17^{* *}$ & $18.55^{* *}$ & $19.15^{\star *}$ & - \\
\hline
\end{tabular}

The values are stated as mean \pm variance; $n=6$ (number of animal). F values $=$ significance at ${ }^{*} p<0.05,{ }^{* *} p<0.01, \mathrm{t}$-value $=$ significance at ${ }^{\mathrm{a}} p<0.05,{ }^{\mathrm{b}} p<0.01,{ }^{\mathrm{c}} p<0.001$. $\mathrm{mEq} / \mathrm{L} / 100 \mathrm{~g}$ signifies mili equivalent/litre/100 g

Table 2: Effect of extracts of $M$. philippica leaves in ethanol induced ulcer rat model.

\begin{tabular}{ccccc}
\hline Group & Treatment and dose & $\mathrm{pH}$ & Ulcer index & \% of protection \\
\hline I & Control $10 \mathrm{ml} / \mathrm{Kg}$ & $2.10 \pm 0.02$ & $5.82 \pm 0.16$ & - \\
II & Ranitidine $200 \mathrm{mg} / \mathrm{kg}$ & $4.36 \pm 0.12^{* *}$ & $2.13 \pm 0.12^{\star}$ & 63.40 \\
III & Aq. Extract $200 \mathrm{mg} / \mathrm{kg}$ & $3.12 \pm 0.09$ & $3.01 \pm 0.64^{* *}$ & 48.28 \\
IV & Me. Extract $200 \mathrm{mg} / \mathrm{kg}$ & $2.61 \pm 0.03^{*}$ & $4.16 \pm 0.37^{* *}$ & 28.52 \\
& F $(3,20)$ & 58.062 & 65.19 & - \\
\hline
\end{tabular}

The values are stated as mean \pm variance; $\mathrm{n}=6$ (number of animal), $\mathrm{F}$ values $=$ significance at ${ }^{*} p<0.05,{ }^{*} p<0.01$, t-value $=$ significance at ${ }^{\mathrm{a}} p<0.05,{ }^{\mathrm{b}} p<0.01,{ }^{\mathrm{c}} p<0.001$.

Table 3: Effect of extracts of $M$. philippica leaves in $\mathrm{NaOH}$ induced rat ulcer model.

\begin{tabular}{ccccc}
\hline Group & Treatment and dose & $\mathrm{pH}$ & Ulcer index & \% of protection \\
\hline I & Control $10 \mathrm{ml} / \mathrm{Kg}$ & $2.96 \pm 0.06$ & $6.4 \pm 0.46$ & - \\
II & Ranitidine $200 \mathrm{mg} / \mathrm{kg}$ & $5.93 \pm 0.20^{* *}$ & $2.28 \pm 0.18^{*}$ & 64.37 \\
III & Aq. Extract $200 \mathrm{mg} / \mathrm{kg}$ & $5.21 \pm 01.22^{* *}$ & $3.12 \pm 0.25^{* *}$ & 51.25 \\
IV & Me. Extract $200 \mathrm{mg} / \mathrm{kg}$ & $3.55 \pm 0.219^{*}$ & $4.23 \pm 0.59^{* *}$ & 33.90 \\
& $\mathrm{~F}(3,20)$ & 4.97 & 65.66 & - \\
\hline
\end{tabular}

The values are stated as mean \pm variance; $\mathrm{n}=6$ (number of animal), $\mathrm{F}$ values $=$ significance at ${ }^{*} p<0.05,{ }^{* *} p<0.01, \mathrm{t}$-value $=$ significance at ${ }^{\mathrm{a}} p<0.05$, ${ }^{\mathrm{b}}$ $p<0.01,{ }^{c} p<0.001$. 


\section{DISCUSSION}

Studies on herbal medicine have been given more preference for its safeness by demonstrating different toxicity tests in laboratory animals. ${ }^{12}$ It is claimed that the plant contains tannins, flavonoids, saponins as phyto-chemical constituents which is efficiently show the anti-ulcer property due to the protection of mucosa against acid by inhibiting $\mathrm{PGF}_{2 \alpha}$ selectively. ${ }^{13}$ Flavonoids are efficiently protect the gastric mucosa against multiple ulcerogenic agents by following several mechanism of action, primarily free-radical scavenging, increased mucus production, antioxidant properties, , anti-secretory activity and inhibiting the growth of Helicobacter pylori ${ }^{14}$ has been extensively confirmed. Different plant extracts having therapeutic effect are selected for inhibition of gastric acid secretion or to stimulation of mucosal defence followed by increase in the mucus formation which is meant for the protection of surface epithelium. ${ }^{15}$ In view of this, the current study was selected to evaluate the potential effect of antiulcer property of $M$. philippica leaves extracts (both methanol and aqueous) by following three different ulcer models such as pylorus ligated, ethanol induced and $0.2 \mathrm{M}$ sodium hydroxide induced rat ulcer models to study the cytoprotective and anti-secretory activity. There is no sign of mortality or toxicity was observed in the course of experiment to the experimental animals. It was reviewed that pylorus ligated ulcer model is vastly predictable, repeatable and smooth model for the evaluation of antiulcer agents which is neither promote ulcerogens nor activated by interfering factors occurring exogenously. ${ }^{16}$ This model may be owed to injury in mucosal barrier, declining of mucosal blood flow level and self absorption of gastric content. ${ }^{17}$ In our experimental study, the intensity of gastric mucosal damage induced by pyloric ligation in rats showed significant change in gastric volume, $\mathrm{pH}$, total acidity content and free acidity content and ulcer index in the experimental animals. In the control group, higher induction of ulcer was observed due to increase in the level of gastric content inside stomach. The mechanism behind pylorus ligation gastric ulcer rat model is inhibition and synthesis of endogenous prostaglandins. ${ }^{18}$ This mechanism point outs the possible cytoprotective effect due to anti ulcerogenic and anti-secretory effect of $M$. philippica leaves extracts. It has been reported that administration of ethanol by oral route produces severe ulceration and elevates lipid peroxide and glutathione level significantly. Formation of gastric lesion by ethanol induction occurs in gastric blood flow which may have a chance for haemorrhage and necrotic growth in aspects of tissue damage due to stasis. Penetration of alcohol to the gastric mucosa causes rapid damage to both cell and plasma membrane which leads to increase permeability in the membrane of intra cellular component for sodium and water. This intracellular accumulation of calcium confirms the etiology behind gastric mucosal injury followed by death of cell and surface epithelium exfoliation. ${ }^{19}$ The process of gastric lesion induction by ethanol is an expeditious and suitable approach which is most preferred for the screening of herbal extract having antiulcer and cyto-protective activity. ${ }^{20}$ The prevalence of ulcer induction by using alcohol is prominent in the stomach and responsible for the leukotriens, mast cell and reactive oxygen species by producing gastric mucosal injury. ${ }^{21,22}$ This ulceration in gastric mucosal cell is also protected by free radical scavengers. ${ }^{23}$ Aqueous extract protects the rat gastric mucosa from ulceration may be a reason for secretion of gastric acid causing gastric cyto-protection reductions induced by ethanol. However, the test extracts showed similar antiulcer activity against $0.2 \mathrm{M} \mathrm{NaOH}$ induced ulcer model and further support the antiulcer potential of the extracts. Both of the extract showed significant antiulcer activity in all three models but comparatively better antiulcer activity was observed in aqueous extract of $M$. philippica which could be attributed to the occurrence of phytoconstituents like of tannins, triterpinoids, saponins, flavonoids, phenols and glycosides.

\section{CONCLUSION}

Above performed studies report reveal that the antiulcer activity of methanol extract and aqueous extracts of $M$. philippica leaves at a dose level of $200 \mathrm{mg} / \mathrm{kg}$ each was tested against different types of experimentally induced ulcer models. The pylorus ligated rat model demonstrates anti-secretory property of the test extract. The aqueous extract at dose level of $200 \mathrm{mg} / \mathrm{kg}$ revealed a significant decrease in ulcer index, gastric volume, total acidity and free acidity but with an increase in $\mathrm{pH}$. The said property showed that the tested extract act by altering the mucosal barrier. In cyto-protective model, administrations of the aqueous extract significantly reduce the ulcer index while no such changes were observed by methanol extract. The presence of flavonoid content is responsible for the gastro protective effect was confirmed. The antiulcer effects of the tested M. philippica plant extracts point out its possible cyto-protectiveness. Therefore, the conclusion may be drawn that the aqueous extract obtained from the leaves of M. philippica possesses potential antiulcer activity in rat model.

\section{ACKNOWLEDGEMENT}

The authors are grateful to School of Pharmaceutical Sciences, Siksha 'O' Anusandhan (Deemed to be University), Bhubaneswar for providing facilities and necessary advice for this research work.

\section{CONFLICT OF INTEREST}

The authors declare no conflict of interest.

\section{ABBREVIATIONS}

H: Hours, min: Minutes; mg: Mili gram; Kg: Kilo gram; v/v: Volume by volume; g: Gram; mEq: Mili equivalent; L: Litre; Aq: Aqueous; Me: Methanol; ml: Mili litre; M. philippica: Mussaenda philippica.

\section{REFERENCES}

1. Kar DM, Rout SK, Moharana L, Majumdar S. Evaluation of anticonvulsant activity of hydroalcoholic extract of Mussaenda philippica on animals. J Acute Dis. 2014;3(1):46-50

2. Bensky D, Clavey S, Stoger E, Gamble A. Chinese Herbal Medicine: Meteria Medica. Third Edition. 2004

3. Arunachalam S, et al. The genus Mussaenda: A phytopharmacological review. J Chem Pharm Res. 2015;7(7):1037-42. ISSN: 0975-7384.

4. Kamurthy H, Viddae J, Dontha S, Rao N, Nampally S. J Planar Chromat- Modern TLC. 2014;27(2):93-6.

5. Kalant H, Grant DM. Principle of medical pharmacology. $7^{\text {th }}$ ed, Elsevier, 2007. ISBN-978-0-7796-9945-2.

6. Vinodhini S, Rajeswari DV. Review on ethnomedical uses, pharmacological activity and phytochemical constituents of Samanea saman (jacq.) Merr. rain tree. Pharmacog J. 2018;10(2):202-9.

7. Mehta D. Ulcer-review on types, anti-ulcer drugs, anti-ulcer medicinal plants, anti-ulcer drug market, diagnostics and current global clinical trials status. Invent Rapid Pharm Pract. 2016;2:1-8.

8. Rath D, Kar DM, Panigrahi SK, Maharana L. Antidiabetic effects of Cuscuta reflexa Roxb. in streptozotocin induced diabetic rats. J Ethnopharmacol. 2016;192:442-9.

9. Rath D, Panigrahy SR, Panigrahi SK, Kar DM, Maharana L. Antidiabetic effect of extracts of Blumea lacera dc. in streptozotocin induced hyperglycemic rats. Int J Pharm Pharm Sci. 2017;9(10). ISSN- 0975-149,

10. Panda PK, Panda DP. Anti ulcer activity of strychnine and its comparison with cimetidine in shay rat. Indian Drugs. 1993;458-61.

11. Marref SE, Benkiki N, Melakhessou MA, Bouzidi S. Acute Toxicity, Antiulcer and Anti-inflammatory effects of methanol extract of Gladiolus Segetum in Rats. Pharmacog J. 2018;10(4):758-62.

12. Fennell CW, Lindsey KL, McGaw LJ, Sparg SG, Stafford GI, Elgorashi EE, et al. Assessing African medicinal plants for efficacy and safety: Pharmacological screening and toxicology. J Ethnopharmacol. 2004;94(2-3):205-17.

13. De Pasquale, Germano R, Keita MP, Sango AR, Lauk L. Antiulcer activity of Pteleopsis suberos. J Ethonopharmacol. 1995;55-8.

14. Fatima S, Heena ST, Qureshi AS. Evaluation of Anti-Ulcer activity of $70 \%$ Hydroethanolic leaf extract of Argemone mexicana Linn. In experimental rats. J of Pharmacy. 2016;6(4):41-50. 
15. Ghangale GR, Tushar M, Jadhav ND. Evaluation of antiulcer activity of Ocimum sanctum in rats. Vet World. 2009;2(12):465-6

16. Manoj KC, Surendra HB, Sanjay KG. Assessment of the antiulcer potential of Moringa oleifera root-bark extract in rats. J Acupunct Meridian Stud. 2013;6(4):214-20.

17. Goel RK, Bhattacharya SK. Gastroduodenal mucosal defence and mucosal protective agents. Indian J Exp Biol. 1991;29(8):701-14.

18. Sujith T, Mohammed F, Nafia K, Muhammed S, Sapna S. Pharmacological review of anti ulcer screening. World Journal of Pharmacy and Pharmaceutical Sciences. 2017; 6(05):1369-1387. ISSN 2278 - 4357.

19. Raju D, et al. Evaluation of Anti-ulcer activity of methanolic extract of Terminalia chebula fruits in experimental rats. J Pharm Sci Res. 2009;1(3):101-7.

20. Patel AB, Prasanna SK, Shastry CS. Antiulcerogenic activity of Moringa oleifera root extract against ethanol-induced gastric ulcer in rats. Int J Pharm Chemical Sci. 2012;1(1):243-9.

21. Oates PJ, Hakkinen JP. Studies on the mechanism of ethanol induced gastric damage in rats. Gastroenterology. 1988;94(1):10-21.

22. Mizui T, Sato $H$. Effect of antiperoxidative drugs on gastric damage induced by ethanol in rats. Life Sci. 1987;41(6):755-63.

23. Vijay L, Upendra K. Phytochemical and acute toxicity of Moringa barks in rats. Int J Biomed Res. 2011;2(10):548-53.

\section{GRAPHICAL ABSTRACT}

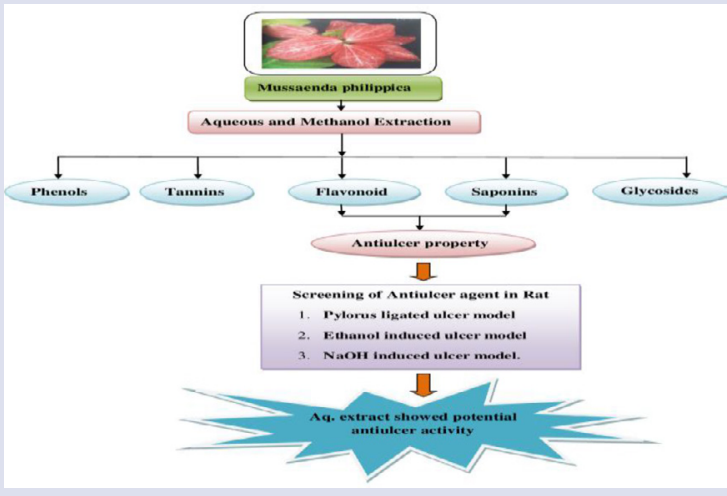

\section{SUMMARY}

- Mussaenda philippica belongs to the family Rubiaceae, is a shrub having therapeutic importance.

- The medicinal property includes cytotoxicity, antipyretic, anti-inflammatory, anti-fertility, antiviral, antioxidant and antibacterial activities, diuretic and mainly effective in laryngopharyngitis and acute gastroenteritis.

- Presences of different phyto-constituents having pharmacological activity were confirmed by following various extraction methodologies.

- Evaluation of antiulcer models by following pylorus ligated ulcer model, ethanol induced ulcer model and $\mathrm{NaOH}$ induced ulcer model. Aqueous extract showed potential antiulcer activity in all the mentioned models.

\section{ABOUT AUTHORS}

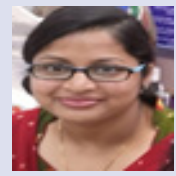

Ms. Rasmita Jena: Presently working as Ph.D scholar, Department of Pharmacology, School of Pharmaceutical Sciences, S 'O' (A Deemed to be University), BBSR, 751003, India.

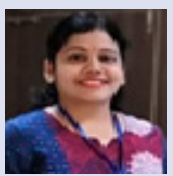

Mrs. Diptirani Rath: Presently working as Assistant Professor, Department of Pharmacology, School of Pharmaceutical Sciences, S 'O' (A Deemed to be University), BBSR, 751003, India.

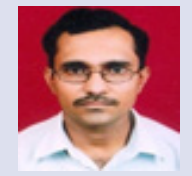

Dr. Durga Madhab Kar: Presently working as Professor and HOD, Department of Pharmacology, School of Pharmaceutical Sciences, S 'O' (A Deemed to be University), BBSR, 751003, India.

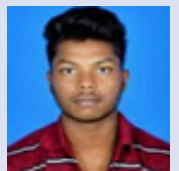

Mr. Kaushik Sur Roy: M.Pharmacy, Department of Pharmacology, School of Pharmaceutical Sciences, S 'O' (A Deemed to be University), BBSR, 751003, India.

Dr. Goutam Ghosh: Presently working as Associate Professor, Department of Pharmacognosy, School of Pharmaceutical Sciences, S 'O' (A Deemed to be University), BBSR, 751003, India.

Cite this article: Jena R, Kar DM, Rath D, Roy KS, Ghosh G. Antiulcer Property of Mussaenda philippica. Pharmacog J. 2019;11(3):6037. 